\title{
Applying Drama and Narrative Structure in ESL Language Education
}

\author{
John W. Maloney ${ }^{1}$ \\ ${ }^{1}$ Tainan University of Technology, Taiwan, R.O.C.
}

\begin{abstract}
The use of dramatic narrative as a pedagogical methodology has been gaining wider application in many fields of education. The rationale for this growth in application is based on significant research into the universal presence of dramatic narrative structures throughout world cultures, and the proven efficacy of using dramatic narrative to contain meaning. This paper outlines analysis of dramatic narrative and proposes a curriculum design aimed at developing skills in creating narrative structures and drama for application in ESL language education.
\end{abstract}

Keywords: drama, ESL, narrative, structure, teaching.

\section{Introduction}

The value of drama-based activities in the classroom is widely acknowledged [1]. One of the main benefits, according to most literature on the subject, is that drama activities generate a creative learning environment [2]. Additionally, creating experiences in the classroom is an important component of learning [3].

In ESL language education, drama is incorporated into curriculum in manners that vary widely from drama exercises and games in conversation classes to the ubiquitous graduation dramas that many university English programs perform each year. However, despite such a wide range of application, there is very little material available to ESL language instructors on how to introduce what a drama actually is. Particularly, there is a lack of material aimed at giving instructors tools to help them guide students in the creation of original drama projects.

A common technique in ESL classes that use creative dramatic techniques is to give students a conflict or problem, and then ask them to solve the ensuing communication breakdown through dialogue: in essence, to enact a short play. The shortcoming in this sort of exercise is the lack of a clear structure to create dialogue that might give students more confidence to fully explore the dramatic situation, and thus employ a richer variety of language opportunities.

Many ESL language programs utilize long-form dramatic projects, such as students developing an original drama for a school celebration or competition, or rehearsing and presenting a pre-written script as a graduation project. But, without an adequate understanding of dramatic structure and elements, students do not have a clear understanding of what a drama actually is, or the tools to work confidently and efficiently in creating one.

One of the goals of creative learning techniques in general, and drama in particular, is to engender a lowanxiety learning atmosphere [4]. In such an atmosphere, students feel more confident, participate more fully, and retain more from their lessons. Research has shown that the use of clear structures and paradigms are an important aspect of reducing anxiety and engendering a creative learning environment. This is because they set very clear guidelines for student participation [5].

The goal of this paper is to outline the basic elements and narrative structure of drama in order to present educators with tools to develop a creative dramatic curriculum that can be easily taught and implemented in the tertiary ESL classroom. It is hoped that this structural approach to the teaching of creative dramatics will give students the tools necessary to empower them in the creation of original dramatic narratives for language practice and improvement. Additionally, the topics covered in this paper may also be useful for instructors leading students in situations where pre-written scripts are used in classroom settings - especially in the analysis and preparation of these scripts for performance.

This paper will present material for curriculum design through an analysis of the three main elements of a dramatic narrative (character, plot, and setting), and an outline of traditional narrative structure. It is the premise of this author, that if these concepts are clearly communicated to students, they will be able, with guidance, to prepare and present original dramatic narratives that will be beneficial for their English language improvement. 


\section{Methodology}

\subsection{Introducing Character}

The most basic element of all drama is character. Until this element is clearly defined, there can be no story. But character is much more than a name or an identity. It is the foundational generative force that drives the narrative

When asking students to contribute ideas for characters in the creation of a drama, the responses will often be occupations (doctor, police officer, teacher), types (old woman, little boy, handsome man), or stereotypes (gangster, movie star, tycoon). These are all good starting points for the creation of character, but simply creating a list of titles or types does not really address the requirements for a drama. For, although there are certain assumed traits that we associate with various character types, titles, and occupations, what do we really know about the movie star, the police officer, or the little boy that makes them distinct and interesting as a character? Nothing really. All we know by a title or type is what might be referred to as a character's role.

The true definition of character is found in need. All characters are defined by their needs. These needs, in turn, drive characters to actions. The results or consequences of these actions generate the emotional dynamics of the drama.

\section{Need}

In order for a character to function in a drama, it must have a strong sense of purpose - a need. In fact, need is what actually determines character, and gives the notion of character its utility in drama. For example, what actually sets the role of a police officer apart from the role of an old woman, or a tycoon, are his or her needs. In order to test this notion, simply think about a single need and apply it to all three roles. Love, for instance. It is easy to see that the need for love to be reciprocated will define the police officer, the old lady, and the tycoon more than their roles. Their distinctions are vastly diminished when the same need is applied to all three, and it is easy to imagine all three characters behaving in very similar fashion in order to achieve their need for love. Change the need to a desire for fame, and again, they are all redefined. You can continue with other needs such as power or money and find the same results. This is not to say that roles (titles, occupations, stereotypes, etc.) don't have a use in determining how a character will develop - but without a clear need, they will most often remain flat and two-dimensional.

A useful categorization of needs for the classroom would be tangible or intangible (in an ESL setting, it might be more optimal to use the terms 'things you can touch,' and 'things you can't touch'). In this manner, all imaginable needs are covered, yet there is a simple distinction between those, which can be obtained in a physical manner and those which cannot. This categorization also gives the language learner clear distinctions wherein to locate vocabulary (physical vs. conceptual terms).

Tangible Needs: physical items that can be gifted, obtained, earned, purchased, won, or lost.

(e.g. money, prizes, food, property, etc.)

Intangible Needs: emotional or rational concepts that can be felt or perceived.

(e.g. survival, safety, justice, trust, love, power, respect, etc.)

The tangible/intangible categorization is a useful tool for introducing the concept of need and how it affects the development of character. For instance, in a particular exercise, the instructor could direct students to come up with only intangible needs (freedom, relaxation, respect, etc.), and then pursue those needs in the development of a short improvised drama. Then, with the same groupings, the instructor could direct students to improvise another drama pursuing only tangible needs (money, food, clothing, etc.). As students advance they might also play with pairing needs from both categories to develop more complex characters and scenarios.

Classroom discussions about need often gravitate towards tangible needs. It is usually only after introducing the concept of intangible need that students start to consider this category. However, once identified, it often becomes a very active part of the discussion, as well as a popular category of need in classroom projects. Thus another benefit of the tangible/intangible categorization is that it seems to draw more attention to the concept of intangible needs - which might otherwise be overlooked or under-explored.

Often, a classroom drama project seems to revolve only around the need (or needs) of the central protagonist. However, it is important to communicate to students that every character has at least one need, however simple it may be, and that they must pursue it in order for their character, and the drama as a whole, to become fully developed. Even a bit character, one that enters just to tell another character a piece of information, has the need 'to communicate'. For an example, we can take the story of Little Red Riding Hood. It is important for the drama that, just like Little Red, the other characters all has their own needs as well. The wolf must eat to survive. 
And perhaps his nature as a predator gives him a physical, or instinctual, need to kill. More advanced types of needs for the wolf might be a need for respect as a fearsome animal, or a need for power that he fulfills by killing. Perhaps, comically, the wolf may be lonely and seek friendship with Little Red, but this need for friendship is overcome by his hunger need. Additionally, the grandmother has several needs - even if we don't see her before she is devoured. Once she is freed from the wolf's belly she may have a need for revenge, or a need for comfort. The hunter too has needs (to save Little Red and Grandma, to display his prowess, to be a hero). The degree to which each character expresses and pursues his or her needs will help to define his or her character, and the quality of the overall drama. Once this concept is clearly understood by students, they can more actively engage in their roles as they develop the drama.

\section{Action}

Need leads to action. When you want something, you naturally take steps to obtain it. If a character is thirsty, they reach for a glass of water. If a character is in love they might approach their love interest with some form of conversation or gift. On the other hand, fear (and the need to be free from fear) might cause them to act bashfully, or run and hide from their love interest. If a character needs money they may engage in work or a task that will pay them for their labor. Or, perhaps they might steal the money. In this regard, all action in a drama can be seen as the result of pursuing a need.

Often students will say that they 'don't know what to do next' when creating a drama. Reminding them to think about their needs can help them to discover their next action. The process of action in a drama is progressive. Each action leads to a reaction, which in turn leads to another reaction, and so on until an ending is achieved. The end of dramatic action can be either the achievement of need by one or more characters (resolution, transformation), or the revelation of the inability to achieve any needs (stasis). Generally, since learning environments favor a task completion paradigm, it may be beneficial to instruct students to pursue endings that resolve as many of the needs of the characters as possible. Obviously, it will not always make sense for every character's needs to be met - but, at minimum, a situation where the main protagonist or antagonist succeeds will give students a sense of completion.

\section{Emotion}

Emotion is directly related to need, because a character experiences emotions relative to their needs being achieved or denied. A character in need of love is elated when that love is reciprocated, lost and heartbroken when not. A character in need of money is happy and relieved when it is available, desperate and anxious when it is not. This direct relationship between need and emotion can be very helpful in training students to create their own dramas. For instance, when students are unsure how to express themselves, they can simply ask themselves to what degree are their needs being met and determine an emotional response to try out.

A useful technique in classroom drama exercises is to encourage students to express themselves with what might be termed 'heightened' or exaggerated emotions. This can serve to counteract the natural human tendency to mute emotional expression in social or public circumstances. This may be because heightened emotional response is, due to its exaggerated quality, clearly not a 'real' emotional response. This in turn alleviates some of the natural anxiety around self-presentation that is inherent in dramatic situations. Students are more aware of pretending when they exaggerate, and thus, paradoxically, it is easier to engage a shy student when they are given the opportunity to overact. Once several students take the initiative to heighten their emotional responses to needs being met or thwarted, the result is rather infectious, and many students who were reluctant to participate on an emotional level engage more wholly in the activities.

\subsection{Introducing Plot}

Plot is often referred to as the narrative of the drama. This is true, but not all narratives are dramatic. For a narrative to become dramatic there needs to be tension. This tension is arrived at through many avenues: disagreement, competition, envy, greed, malice, desire, curiosity, etc. At its most basic level, tension is the result of a need not being achieved, or in the process of being achieved. Thus, plot is really a term for the chronicle of the difficulties (or problems) encountered in the pursuit of need. Without difficulties, there would be no drama. For instance, if Cinderella's stepmother were a kind and fair woman, there would be no story - at least not one that would be of much interest. Thus at the heart of any truly dramatic narrative are the obstacles to needs. These problems, or difficulties, are often given the general term 'conflict'. A very popular way of categorizing conflict according to this general definition is: 


$\begin{array}{lll}\text { Man } & \text { vs. } & \text { Man } \\ \text { Man } & \text { vs. } & \text { Nature } \\ \text { Man } & \text { vs. } & \text { Himself }\end{array}$

This categorization is useful, but may be too general. Additionally, it seems to imply that all conflicts share the same basic nature, and differ only by the parties involved. I would suggest that a more useful way of understanding the obstacles, or problems, a character encounters in pursuit of need would be to categorize them into two basic types: conflict, and complication.

\section{Conflict}

Conflict, according to this categorization, has two major types. First, is the involvement of two or more characters in the pursuit of a single need (e.g. two men love the same woman, a group of contestants compete for a prize, two armies in combat, a political election). The second type of conflict is the involvement of two or more characters in pursuit of different, or conflicting, needs (e.g. a couple want to go to the movies - she wants to see a romance, he wants to see an action film, political parties competing in an election, etc). These conflicts can arise between any combination of individuals or groups:

$\begin{array}{lll}\text { Individual } & \text { vs. } & \text { Individual } \\ \text { Individual } & \text { vs. } & \text { Group } \\ \text { Group } & & \text { vs. Group }\end{array}$

\section{Complication}

The second type of narrative obstacle, according to this new categorization, is complication. Complication arises when the pursuit of need (by a single character, or a group) is thwarted or delayed by factors, either internal or external to the character(s), which do not involve the needs of any other character(s). To put it simply, a complication is a problem without a sentient adversary. Some examples of complications would be: fear, lack of physical strength, natural disasters, a timetable, etc. Complications can generally be categorized as follows:

$\begin{array}{lll}\text { Individual } & \text { vs. } & \text { Self } \\ \text { Individual /Group } & \text { vs. } & \text { Nature } \\ \text { Individual / Group } & \text { vs. } & \text { Circumstance }\end{array}$

Understanding the distinction between conflicts and complications can lead to more focused types of group activities. For instance, in a particular class session, students could be instructed to develop short dramas involving only complications. The nature of addressing complications is such that people tend to work together to solve the problem. In this manner, the task work of each group will have a strong sense of unified purpose to overcoming the obstacle. This is a good tool for developing harmonious group dynamics. Conversely, another class session could be devoted to exploring only conflict type dramas. Here the task emphasis could be placed on resolving the conflicts. It is important to note that conflicts, by their nature, tend to develop into more argumentative situations than complications. When introducing conflicts into class work, it may be wise to give a good introduction on their volatile nature at the onset so that students are not too surprised by the types of interactions that may develop. On the other hand, it is sometimes the volatility of conflicts, and the opportunity to explore them in a safe setting, that stimulates student interaction.

Aristotle, in his Poetics, states that complex plots make for better plays [6]. Although not all of Aristotle's dramatic ideas have held their ground in the modern age, the notion of a complex plot being more interesting and enjoyable is still practically a truism. Perhaps the most efficient way to develop a plot's complexity is by the addition of conflict and complication. The more problems a character (or characters) encounter, the more interesting and enjoyable the drama becomes. With beginning students, it may be enough to have them deal with single conflicts or complications (or a few combined). However, as students become more advanced, they should start to play with multiple combinations of conflict and complication. In doing so, they will start to discover more elaborate and interesting plots.

Once students become aware of the benefits of increasing the complexity complications, the problem of the 'blank canvass' typically evaporates. Furthermore, the stimulation of the narrative as a result of increased complexity adds not only interest to the story, but also more individual opportunities for students to participate in the drama. Indeed, the more complex the plot becomes, the more each character has to do in order to resolve the drama. Once this attitude is adopted, the process of creating a narrative truly becomes a task-based activity. 


\subsection{Introducing Setting}

Setting is an often overlooked or under-appreciated element in the structure of a drama. Where a drama happens is as important as what happens. Consider, for instance, the popular movie Titanic. At its most basic, it is a love story with multiple conflicts and complications. But would it be as interesting a story if the characters had simply met passing on the street? Could they have even met in that manner? In this instance, setting is crucial to the plot, and even adds an over-arching level of complication to the narrative. The setting itself is a complication. Perhaps the two most common mis-steps when creating a drama are to:

1: Make no active decision whatsoever about the setting, and thus have no clear concept of the world in which the action takes place.

2: Assume that the action takes place in a setting that fits too neatly to the characters, and thus results in a clichéd, or unstimulating environment.

Either of these mis-steps at the onset of creating a drama can result in many missed opportunities for dramatic enhancement.

In the first instance (1, above), if no active decision regarding setting is made, then the resulting indeterminacy creates a flat and indistinct world. The opportunity for setting to play an active part in the drama is lost. This is often the case in basic drama activities when students are instructed to adopt two characters and pursue a dialogue. They have no idea where they are, and thus lose the opportunity for setting to enhance their situation. Take, for example, a student-generated dialogue between a boss and an employee. If the students make no clear choice for setting, then the drama will by default seem to happen in an indistinct 'office' or 'work' location. But if the students ask themselves particularly what sort of business is involved (e.g. shoe store, restaurant, bank, amusement park, etc), then they will have a much clearer sense of how to set their needs and pursue them. For example, the needs of bank teller, a waitress, and a Ferris wheel operator are all quite specifically different.

In the second situation (2, above), even if students do make an active choice, they often rely on typical settings in relation to their characters. The aforementioned boss and employee are set in a shoe store, office, or restaurant (typical locations for this relationship). But if students take a further step in their understanding of setting, then whole new opportunities for dramatic development arise. Again, take the boss and the employee but this time their setting is in a jail cell, or in a hot air balloon (perhaps one that is losing its air). These nontraditional settings give the drama specific, yet highly enhanced opportunities for development.

Non-traditional settings can also make an old story new. One need only look at the relationship of West Side Story to Romeo and Juliet to find a clear example. Here the major setting change is temporal, from preRenaissance Verona to modern mid-town Manhattan. The characters do not change drastically, but the opportunities for conflict and complication are opened to new possibilities. Issues such as ethnicity and class are brought to the fore.

Furthermore, setting can have an effect on more than just the theme of a drama. Once again consider Little Red Riding Hood. But now, instead of the familiar setting of a journey from the village into the forest (a place of danger and mystery), relocate it to a modern inner city, where the forest becomes the subway system (a place of danger and vulnerability in many cities). Now the setting enables the familiar story to be enhanced by the incorporation of new characters and problems. Even more, it encourages the transformation of characters into new forms. Perhaps the wolf is no longer an animal, but rather a menacing gangster. The hunter could be a detective on his trail. It is the same story outline, but now with new character types and many opportunities for students to discover character and plot. All this is the result of one clear choice in setting.

The power of setting to create dramatic opportunities is perhaps the most under-utilized aspect of creative dramatic exercises. If students do not make clear choices in the setting of their dramas, they will most often fall back on vague or uninteresting settings, which will cut them off from vast opportunities for character and plot development. If, on the other hand, students learn to explore alternate and non-traditional settings, there is no limit to the creative potential that they may unleash.

\subsection{Introducing Narrative Structure}

When viewed as a whole, the work of organizing the various needs and actions of characters into a complex narrative that builds dramatic tension seems to be a rather daunting task. But, if the work of creating a narrative is broken down into its constituent stages, it becomes much more manageable. This is the key notion to communicate to students at the onset of a creative dramatic project.

\section{What is Narrative Structure?}


Storytelling is one of the oldest forms of teaching. In some societies it is the only form of teaching. Despite a multitude of technological advancements and methods of transmission, a simple narrative is still the cornerstone of the art of teaching. Narrative is used to express ideas, persuade others to accept ideas, and to understand the world.

Narrative was at one time a heated topic in the field of literature. Walter Fisher extended it to a much wider field which includes all forms of rhetoric actions. His Narrative Paradigm lays a foundation for narrative criticism in the field of Rhetoric [7]. When Fisher proposes the concept of Narrative Paradigm, he provides an understanding of what narrative is. He refers to narrative as "a theory of symbolic actions-words and/or deeds - that have sequence and meaning for those who live, create, or interpret them" [7, pp. 2].

When narrative is layered into a course structure, learning becomes embedded in a more natural context that engages students affectively as well as cognitively. This type of engagement helps them retain details and make meaning of information and also increases the impact of and learning potential in your course.

A narrative structure or, what can also be called the story-form, organizes facts, ideas, concepts, etc. in a coherent and emotionally engaging way. In discussion of the tools of oral language and the imaginative dimensions of Mythic understanding, we identify the story as crucial in early learning; it is the tool that enables us to bring curriculum content and emotion together to make knowledge more fully meaningful to the student. That remains largely true for older students, but the kind of story that engages them is different from the basic story structures more common in early years. The term narrative is now used to refer to the story-form shaped by the emotional and imaginative features of literacy.

A narrative is a continuous account of a series of events or facts that shapes them into an emotionally satisfactory whole. It has in common with a story that shaping of emotion, and so the words are often used synonymously, but it is different in that narratives can be less precisely tied into a tight story, less concerned with emotion, more varied, more open, more complex. That is, the term narrative is used to indicate the greater variety and openness of the stories that prove most useful as students become fluently literate. Like story, narrative preserves the importance of shaping events and facts to affect emotions.

The traditional narrative structure of drama is rather simple and easy to communicate to students. This is because they encounter it on a regular basis. For, although most modern students do not attend the theatre or read plays, this structure is evident in most modern movies and television dramas. However, despite their familiarity with traditional dramatic structure, many students are unclear on how to identify and analyze the various stages in a dramatic narrative. Fortunately, once given a clear structural outline, and provided with simple terminology for these stages, most students are able to easily understand and discuss these stages.

In the late part of the 19th century, German novelist and playwright Gustav Freytag outlined five stages of dramatic progression that have become the basis for much of our modern understanding and analysis of dramatic structure [8]. Freytag termed these stages Exposition, Rising Action, Crisis, Falling Action, and Dénouement. These stages can be briefly defined as follows:

Exposition: introduces characters and sets the scene.

Rising Action: introduction of the conflicts or complications.

Crisis: the point of no return, the moment of choice.

Falling Action: the final or major confrontation.

Dénouement: the resolution of the action of the drama.

This five-stage structural delineation is very applicable to classic and early modern theatre styles, and has a strong relationship to many modern dramas, but the terminology and the fine distinctions between the stages could be alienating in an ESL classroom setting. For the purpose of clearly communicating the key elemental stages, I would suggest using a simplified four-stage structure incorporating the terms Introduction, Action, Crisis, and Resolution. Below, I will outline each of these stages in a manner that may be useful in an ESL classroom setting.

\section{Introduction}

The introduction is the opening stage of the drama. It is here that setting is established and we meet the central character(s) and learn their needs. In this stage, we may also learn something of the problems (conflicts, complications) that face the central character(s). The introduction is usually a very brief stage, comprising only a scene or two at most. 


\section{Action}

This stage can be summed up in the phrase 'something happens.' In this stage we will be introduced to the larger problems (conflicts, complications) that the characters will encounter. It is here that the character(s) may experience a change in their condition, or embark on a journey. It is also here that the main themes of the drama are developed. New characters may also appear in this stage as well. The action stage can consist of many scenes in many locations, all building the tensions between the various characters in the drama. The action stage is the longest stage of the dramatic structure, usually comprising at least half of the content of the story, and often much more.

\section{Crisis}

The crisis stage is the point in the drama where the central character(s) must express and/or work out the major problem(s) (conflicts or complications) of the narrative. It is the point of no return, and very often results in one or more character experiencing a change of condition or nature, sometimes very extreme. As in previous stages, new characters may appear in the crisis stage. This stage is most often brief, consisting of one to a few scenes of high intensity or energy.

\section{Resolution}

The resolution is the expression of the result of the crisis, and an indication of what the future may hold. It is most often a brief stage consisting of a scene or two at most. It is possible, but not common, for new characters to appear in the resolution stage. In general, there are two types of resolutions: dénouement and catastrophe. Dénouement, French for 'untying the knot,' is most often associated with comedies, and is the stage in the drama where foibles and misconceptions come to light. The end of a comedy is generally expressed as a return to normalcy. The second type of resolution, catastrophe, is the ancient Greek term for 'overturn,' and is most often associated with tragedies, or serious dramas. In a catastrophic resolution, the world, or at least a character, has experienced a change of great magnitude. They will never be the same again.

These two forms of resolution, dénouement and catastrophe, are often referred to in common vernacular as 'happy' and 'sad' endings, but this simple binary does not allow for the many subtle variations, which can occur in these two forms of resolution. For example, at the end of a tragedy or serious drama, a character that has experienced an intense change of condition might be happy for the newfound insight they have gained. Or, conversely, at the end of a comedy, a character may be embarrassed or angry about the jokes played on him or her during the action of the play. For the purpose elucidating these two types of resolution in terminology appropriate to an ESL classroom setting, I would propose describing these two forms of resolution as 'a return to normal' (dénouement), and 'things have changed' (catastrophe).

\section{Conclusion}

It is the hope of this author that a clear understanding of the basic elements of drama (character, plot, and setting), and the traditional structure of narrative (introduction, action, crisis, resolution), will enable instructors to develop curriculum for the incorporation of creative drama projects that will engage and challenge their students. It is further hoped that a greater understanding and facility with these elements will empower students to take bold steps into the rich territory afforded by dramatic activity, where they can confidently approach the work of creating original dramas.

\section{References}

[1] A. Maley and A. Duff, Drama Techniques in Language Learning: A Resource Book of Communication Activities for Language Teachers, Cambridgeshire, UK, Cambridge University Press, 1982.

[2] D. Heathcote, L. Johnson, and C. O'Neill, Dorothy Heathcote: Collected Writings on Education and Drama, London, UK, Hutchinson, 1984.

[3] G. Wells, "Instructional conversation in the classroom: Can the paradox be resolved?" presented at the Annual Convention of the American Educational Research Association, San Diego, CA, April 16, 2009.

[4] J. Piirto, Understanding Creativity, Scottsdale, AZ, Great Potential Press, 2004. 
[5] D. Starbuck, Creative Teaching: Getting It Right, London, UK, Continuum, 2006.

[6] Aristotle (trans. G. F. Else), Aristotle: Poetics, Ann Arbor, MI, University of Michigan Press, 1967.

[7] W. Fisher, "Narration as a Human Communication Paradigm: the Case of Public Moral Argument," Communication Monographs, vol. 51, pp. 1-23, March, 1984.

https://doi.org/10.1080/03637758409390180

[8] G. Freytag (trans E. J. MacEwan) Technique of the Drama: An Exposition of Dramatic Composition and Art, Chicago, IL, Scott, Forseman and Co., 1900. 